\title{
Visibility of the lateral collateral ligaments in routine computed tomography of the ankle
}

\author{
Johannes Gossner
}

Received: 28 October 2009/Accepted: 26 November 2009/Published online: 11 December 2009

(C) Springer-Verlag 2009

Sir,

I have read with great interest the article of Hua et al. [2] in a recent issue. They reported the detailed cross-sectional anatomy of the lateral collateral ligaments of the ankle on computed tomography (CT) and magnet resonance imaging (MRI). They used anatomic specimen and coated the ligaments with contrast media for CT imaging. Whether the ligaments could also be seen on CT scans in vivo was not addressed, but this could be a clinical relevant issue. Here routine CT scans of the ankle were reviewed. The sample consisted of eight patients; all patients were examined for purposes other than acute trauma to the ankle (imaging of orthopaedic hardware, arthrodesis, osteomyelitis, suspected complex regional pain syndrome) and had no clinical suspicion of ankle sprain. All patients were examined using the same 16-slice scanner with identical parameters (slice thickness $0.5 \mathrm{~mm}, 50 \mathrm{~mA} \mathrm{~s}, 120 \mathrm{kV}$ ) and were reviewed on a standard workstation. The anterior talofibular ligament could be clearly depicted in all patients as a hyperdense ligament (Fig. 1). The posterior talofibular ligament could be depicted in five of the eight patients and the calcaneofibular ligament could be depicted completely in three of the eight patients and in part in another two patients.

Imaging of the lateral collateral ligaments is possible using arthrography, sonography and MRI, with MRI being the imaging method of choice in complicated or equivocal cases. CT has mostly been used to search for subtle

\section{J. Gossner $(\square)$}

Department of Clinical Radiology,

Göttingen-Weende Teaching Hospital,

An der Lutter 24, 37075 Göttingen, Germany

e-mail: johannesgossner@gmx.de
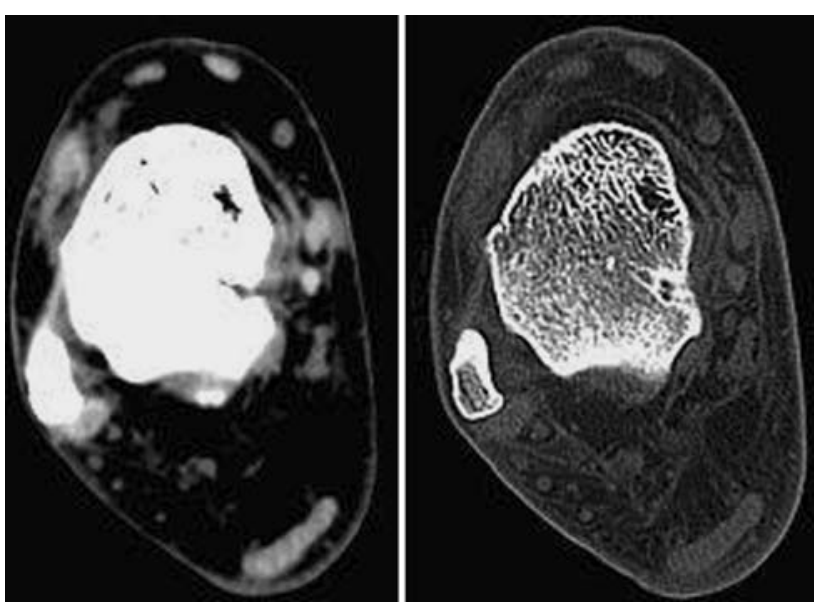

Fig. 1 Axial slices of a computed tomography of the ankle in a soft tissue window (left) and a bone window setting (right). The anterior talofibular ligament could be easily depicted as a slight hyperdense ligament, especially in the soft tissue window setting

fractures in complicated ankle sprains, but there are also a few reports about imaging of the ligaments $[1,3,5]$. In this small series the anterior talofibular ligament could be seen in all patients and the other ligaments in a large portion of patients. An intact anterior talofibular ligament could help to rule out a rupture of the lateral collateral ligaments, because it is the first to be torn in ankle sprains. This approach has been recently shown to be reliable for the imaging of the cruciate ligaments of the knee in CT imaging [4]. So clearly a large study to compare MRI and $\mathrm{CT}$ is warranted to establish the exact role of CT imaging of the lateral collateral ligaments and to make sure we use the full potential of the widespread available and often performed CT scans of the ankle. 


\section{References}

1. Flusser G (2004) Ankle sprain: CT appearance. IMAJ 6:121

2. Hua J, Xu JR, Gu HY, Wang WL, Wang WJ, Dang X, Lu Q, Ding WL (2008) Comparative study of the anatomy, CT and MR images of the lateral collateral ligaments of the ankle joint. Surg Radiol Anat 30:361-367

3. Meyer JM, Hoffmeyer P, Savoy X (1988) High resolution computed tomography in the chronically painful ankle sprain. Foot Ankle 8:291-296
4. Mustonen AOT, Koivikko MP, Haapamaki VV, Kiuru MJ, Lamminen AE, Koskinen SK (2007) Multidetector computed tomography in acute knee injuries: assessment of cruciate ligaments with magnetic resonance imaging correlation. Acta Radiol 48:104-111

5. Solomon MA, Gilula LA, Oloff LM, Oloff J (1986) CT scanning of the foot and ankle: 2. Clinical applications and review of the literature. AJR 146:1204-1214 